\title{
BMJ Open Intersectional role of paternal gender- equitable attitudes and maternal empowerment in child undernutrition: a cross-sectional national study from India
}

\author{
Anupam Joya Sharma (D), Malavika Ambale Subramanyam
}

To cite: Sharma AJ,

Subramanyam MA. Intersectional role of paternal gender-equitable attitudes and maternal empowerment in child undernutrition: a cross-sectional national study from India. BMJ Open 2021;11:e047276. doi:10.1136/ bmjopen-2020-047276

- Prepublication history and additional supplemental material for this paper are available online. To view these files, please visit the journal online (http://dx.doi.org/10.1136/ bmjopen-2020-047276).

Received 25 November 2020 Accepted 14 July 2021

D) Check for updates

(c) Author(s) (or their employer(s)) 2021. Re-use permitted under CC BY-NC. No commercial re-use. See rights and permissions. Published by BMJ.

Social Epidemiology, IIT Gandhinagar, Gandhinagar, Gujarat, India

Correspondence to Anupam Joya Sharma; anupam.sharma@iitgn.ac.in

\section{ABSTRACT}

Objectives To investigate the role of the intersection of maternal empowerment, paternal gender-equitable attitudes, and household wealth in stunting and severe stunting among underfives in India.

Design Cross-sectional study.

Setting Community-based setting, nationally

representative household survey from India.

Participants We used a sample of 22867 mother-fatherchild triads from the fourth round of India's National Family Health Survey (2015-2016). Our inclusion criterion was children below the age of 5 years. The exclusion criterion was a lack of information on paternal gender-equitable attitudes and maternal empowerment. Observations with missing data on any of the covariates were also excluded. Primary outcome Stunting and severe stunting among underfives in India.

Results Our survey-adjusted logistic regression models revealed that even among children from poorer households, those with either an empowered mother or a father with gender-equitable attitudes versus those with none such parents, had a lower odds of stunting (adjusted OR (AOR): $0.92,95 \% \mathrm{Cl}: 0.84$ to 1.02 ) and severe stunting (AOR: $0.87,95 \% \mathrm{Cl}: 0.77$ to 0.98 ), independent of all covariates. We also found substantially lower odds of severe stunting in groups with parental concordance in a woman-friendly outlook, whether non-affluent (AOR: 0.80, $95 \% \mathrm{Cl}: 0.67$ to 0.94 ) or affluent (AOR: $0.50,95 \% \mathrm{Cl}: 0.38$ to 0.67 ).

Conclusion We argue that while women's autonomy could reduce the risk of child undernutrition, focusing on men's attitudes towards gender equity also holds promise for reducing undernutrition. Our findings not only underscore how patriarchy is embodied in undernourished children, but also suggest programmatic interventions to address this deep-rooted scourge in India.

\section{INTRODUCTION}

Undernutrition is a major public health problem, causing more than half of all deaths of children under 5 years (underfives) globally. ${ }^{1}$ However, the burden of undernutrition is higher among the World Bank
Strengths and limitations of this study

- First study to assess the influence of intersectional parental characteristics on child undernutrition in India.

- Employed a sample from a nationally representative survey (2015-2016).

- Use of a smaller sample of father-mother-child triads which had data on gender-related attitudes of the parents limits generalisability.

- Limitation due to social desirability bias in measurement of self-reported gender-equitable attitudes.

categorised low/middle-income countries such as India. ${ }^{2}$ Despite several programmatic efforts to improve the nutritional status of children in the country, the latest nationally representative survey reported a $38 \%$ prevalence of undernutrition among underfives in India. ${ }^{3}$ Research from India has highlighted the major role of several factors such as household wealth, maternal education, and maternal health in influencing a child's nutritional status. ${ }^{4}$ A growing body of recent studies also suggest a relationship between maternal autonomy and child undernutrition. ${ }^{5}$ However, in a patriarchal society such as India, women's autonomy and access to socioeconomic resources are mediated mostly by their husbands or elderly men in the households. ${ }^{6}$ Moreover, such control of women's movement and behaviour by men could lead to low prioritisation of women's health in patriarchal households. ${ }^{7}$ Since maternal health is strongly associated with child's health, ${ }^{8}$ negligence of women's health could further result in poorer child health.

On the other hand, global research has shown that men's involvement in reproductive and women's health has a protective effect on women's and children's health. ${ }^{9} 10$ 
However, cultural and social factors in patriarchal societies restrict women's access to health-promoting resources and inhibit men from participating in decision-making related to women and children. ${ }^{11}$ Studies from patriarchal societies such as Bangladesh and Nepal have reported the prevalence of social stigma and embarrassment around men's involvement in "women's issues."12 13 In India too, evidence suggests that several societal factors hinder men's involvement in women's healthcare. ${ }^{14}$ Men's role in a household is understood as that of a 'provider' and 'protector ${ }^{15}{ }^{16}$; diverting from these norms by helping one's wife in cooking and the care of children could result in stigma and sanction by other men. ${ }^{17}$ Prevalence of such a sociocultural stigma suggests a lack of men's participation in women and childcare in patriarchal societies such as India.

While India-based research on men's participation in women's health and childcare is limited, one study from India has shown that men's knowledge about women's health and possession of a gender-equitable attitude positively influence maternal healthcare utilisation and also increase women's autonomy related to their healthcare. ${ }^{14}$ We argue that the husband/partner's gender-equitable attitudes could not only have a positive effect on the wife's health, but also result in better nurturing of the child. This suggests that having parents with a woman-friendly outlook-a father with gender-equitable attitudes plus an empowered mother-might lead to better health of the child. However, it is also likely that in a patriarchal society, cultural norms place the wife in a disempowered position despite her husband possessing gender-equitable attitudes. One explanation for this disempowerment in such women could be their internalisation of patriarchy ${ }^{18}$ despite being married to husbands with gender-equitable attitudes. Similarly, the widespread Indian practice of marital relationships being forged by families and not the two individuals entering matrimony ${ }^{19}$ could result in women with a strong sense of independence being married to men who believe in patriarchal traditions. Such marital matches with a mismatch in ideas regarding women's autonomy might have practical consequences for decision-making related to child rearing, for instance, in matters related to diet or healthcare.

Our study aims to explore the complex relationship of paternal gender-equitable attitudes and maternal empowerment with child nutritional status. We apply the concept of intersectionality, ${ }^{20}{ }^{21}$ a lens which views the social position of an individual within a macro system of intertwining oppressions. This perspective argues that individuals occupy social locations along multiple axes of hierarchy and could simultaneously enjoy a privileged position on one axis and be disadvantaged on another. For instance, a child with a father with gender-inequitable attitudes but with an empowered mother could enjoy the privilege of being nurtured by her mother, but be disadvantaged because of lower levels of paternal nurturing within the house, since taking care of the child is conventionally considered as a woman's responsibility. We hypothesised that paternal gender-equitable attitudes and maternal empowerment are two axes of (in) equality that not only operate together but also interact between themselves in complex ways to affect the nutritional status of their child. Since household wealth has a strong influence on child nutritional status in India, ${ }^{22}$ we additionally included household wealth as the third axis in our intersectional analysis. The research question addressed in this study was:

How do various intersections of paternal genderequitable attitudes, maternal empowerment and household wealth influence a child's undernutrition status (stunting) in India?

\section{METHODS}

\section{Data sources and the sample}

We draw our data from the fourth round of the Demographic and Health Survey of India (NFHS-4). ${ }^{3}$ The crosssectional survey was carried out under the supervision of the Ministry of Health and Family Welfare, Government of India, with the technical assistance from the United States Inner City Fund International, Maryland, USA. Data were collected during 2015 and 2016 from 601,509 households. We merged two files, the children recode (data on children aged $0-5$ years) and the couples recode (couple-level data) to generate father, mother and child triads for our analysis. Anthropometric data were available for 233695 underfives. However, since information on maternal autonomy and paternal gender-equitable attitudes were not available for a majority of the children, our analytical sample comprised 22867 underfives after exclusion of all observations missing data on relevant variables. The records for these 22867 children were linked with information from their 22867 mothers and 22867 fathers. Our inclusion criterion was children below the age of 5 years. Correspondingly, the exclusion criterion was the lack of information on paternal gender-equitable attitudes and maternal empowerments. Moreover, those observations with missing data on any of the covariates were also excluded from our analysis.

\section{Outcome variables}

Stunting or a low height-for-age suggests an inhibition of a child's linear growth potential and indicates chronic undernutrition. Therefore, we chose stunting and severe stunting as the primary outcomes (binary) for our study and assessed them according to the WHO growth standards. ${ }^{23} \mathrm{~A}$ child with a $z$ score less than -2 was considered stunted and if below -3 , was considered severely stunted.

\section{Independent variables}

The intersectional groups

We drew from the concept of women empowerment suggested by Kabeer ${ }^{24}$ and operationalised women's level of empowerment using variables indicating women's participation in decision-making (related to healthcare, household purchases and visits to friends/relatives and 
husband's earnings), perceptions about wife beating (whether beating by husband was justified in different situations), ownership of land and house and current working status (has a job or not) (online supplemental file). We assigned the value of 1 to each response that indicated the wife's involvement in decision-making, if the wife disapproved wife beating, owned any land, owned a house and if the wife had a job. On summing, the values of this measure ranged from 0 to 12 . We further dichotomised this measure by splitting at the median (median $=8$ ).

Husband's gender-equitable attitudes was operationalised using the variables indicating men's attitudes towards women's involvement in decision-making (healthcare and household purchases), whether they thought that it was justified for a wife to refuse sex in different situations and asking him to wear a condom, attitudes towards wife beating, and attitudes related to contraception. We assigned the value 1 to each response that indicated the husband favoured wife's participation in decision-making, disapproved wife-beating, perceived refusal of sex by wife as justified, perceived the request of condom use by women as justified, and perceived contraception as not just women's responsibility (online supplemental file). On summing, the measure had values ranging from 0 to 16 . We then dichotomised the measure by splitting at the median (median=14). Although this median value of 14 is high given the $0-16$ range of gender-equitable scores, a comparison of this value with the all-India sample of men (median=14) showed identical figures. Fathers with gender-equitable scores equal to or higher than 14 were classified as 'fathers with higher gender-equitable attitudes,' otherwise as 'fathers with low gender-equitable attitudes.'

A household wealth index was created using information on the ownership of several consumer goods and household characteristics, such as availability of clean drinking water, ownership of television and so on. ${ }^{3}$ Such a measure for assessing household wealth has been previously identified to be a robust indicator of financial status in the Indian context with greater internal coherence. ${ }^{25}$ The dataset included information on household wealth quintiles (richest, richer, rich, poor and poorest) based on these scores. However, we merged the richer and richest quintiles to represent the affluent; and the rich, poorer, poorest to represent the non-affluent categories.

Six intersectional groups were created representing the intersection of the three axes:

1. Concordant-high and affluent group: children having a father with high gender-equitable attitudes, a mother with high levels of women empowerment (labelled 'high' because we assumed that this pairing represents greater woman-friendly environment) and belonging to an affluent household.

2. Concordant-high and non-affluent group: children having a father with high gender-equitable attitudes, a mother with high levels of women empowerment and belonging to a non-affluent household.
3. Discordant affluent group: children having a father with high gender-equitable attitudes but a mother with lower levels of women empowerment or having a father with low gender-equitable attitudes but an empowered mother; and, belonging to an affluent household.

4. Discordant non-affluent group: children having a father with high gender-equitable attitudes but a mother with lower levels of women empowerment or having a father with low gender-equitable attitudes but an empowered mother; and, belonging to a non-affluent household.

5. Concordant-low and affluent group: children having a father with lower gender-equitable attitudes, a mother with low levels of women empowerment (labelled 'low' because we assumed that this pairing represents low levels of woman-friendly environment) and belonging to an affluent household.

6. Concordant-low and non-affluent group: children having a father with lower gender-equitable attitudes, a mother with low levels of women empowerment and belonging to a non-affluent household.

\section{Sociodemographic indicators}

The covariates included in our analysis were father's total years of education, mother's total years of education, religion and caste of the parents, age of the father (in years), age of the mother (in years), place of residence (rural/ urban), gender of the child (male/female), birth order of the child and mother's body mass index (BMI).

\section{Statistical analyses}

We first calculated the prevalence of stunting and severe stunting among the underfives across all intersectional groups. Later, we fitted survey-design adjusted logistic regression models to estimate the association of the six intersectional groups with the outcomes: stunting and severe stunting. We added the following covariates to our logistic models (separate for each outcome): father's education, mother's education, religion, caste, age of the father, age of the mother, place of residence, gender of the child, birth order of the child and maternal BMI. Our models also accounted for the clustering due to the sampling design and the women's sample weight. Alpha was set at 0.05 .

All survey-adjusted logistic regression models were run in Stata V.12. ${ }^{26}$

\section{Ethical considerations}

We used de-identified Demographic and Health Survey data for India from 2015 to 2016 . $^{3}$ The survey had received ethics approval from the institutional review board of International Institute of Population Sciences, Mumbai, India. Written informed consent was taken from all adult participants. In the case of data collected from minors, consent was taken from their parents.

\section{Patient and public involvement}

No patients or public were involved in this research. All analyses were based on publicly available secondary data. 
Table 1 The distribution of stunting and severe stunting (\%) among Indian underfives across the six intersectional groups $(n=22867)$

\begin{tabular}{|c|c|c|c|c|}
\hline \multirow[b]{2}{*}{ Intersectional groups } & \multicolumn{2}{|c|}{ Stunting } & \multicolumn{2}{|c|}{ Severe stunting } \\
\hline & $\mathbf{n}$ & Prevalence (\%) & $\mathbf{n}$ & Prevalence (\%) \\
\hline Concordant-high and non-affluent group & 1118 & 41.65 & 457 & 17.03 \\
\hline Discordant non-affluent group & 3182 & 43.09 & 1331 & 18.03 \\
\hline Discordant affluent group & 984 & 26.23 & 359 & 9.57 \\
\hline Concordant-low and affluent group & 661 & 27.18 & 268 & 11.02 \\
\hline
\end{tabular}

\section{RESULTS}

\section{Descriptive results}

The mean maternal age in our sample was 27.42 years $(\mathrm{SD}=5.12)$, mean paternal age was 31.86 years $(\mathrm{SD}=6)$, and mean child age was 2.04 years $(\mathrm{SD}=1.40)$. About $52 \%$ of the children in our sample were boys and a majority $(\sim 60 \%)$ were first or second in birth order. About $74 \%$ of the mother-father-child triads were urban dwellers and about $68 \%$ belonged to poorer households. The prevalence of stunting and severe stunting were considerably low across the affluent intersectional groups than among groups that were non-affluent (table 1). Within a given affluence category, concordant-high and discordant groups had a lower prevalence of stunting (and severe stunting) versus concordant-low groups.

\section{Results from intersectional analysis}

Results from survey-adjusted logistic regression models showed that children belonging to the concordant-high and affluent group had the lowest odds (adjusted OR (AOR): $0.56,95 \%$ CI: 0.46 to 0.67 ) of stunting compared with those belonging to concordant-low and non-affluent group (table 2), independent of their father's education, mother's education, religion, caste, age of the father, age of the mother, place of residence, gender of the child, birth order of the child and maternal BMI. We also found that independent of all covariates, children from the discordant non-affluent group, compared with the concordant-low and non-affluent group, had lower odds of stunting (AOR: $0.92,95 \%$ CI: 0.84 to 1.02 ) and severe stunting (AOR: $0.87,95 \%$ CI: 0.77 to 0.98 ). Findings for severe stunting showed one notable pattern: substantially lower odds of severe stunting in both the groups with parental concordance in woman-friendly outlook, whether affluent or non-affluent.

A greater maternal BMI, more years of mother's and father's education, and a lower birth order of the child were associated with lower odds of stunting and severe stunting in our adjusted logistic regression models.

\section{DISCUSSION}

Our intersectional analysis using a large community-based sample of parents-child triads suggests that being raised by parents who are more woman-friendly could lower the risk of their child being undernourished compared with being raised by less woman-friendly parents. Previous research from India has primarily focused on the influence of maternal autonomy on child nutrition. ${ }^{5}$ While a husband's gender-equitable attitudes may have been shown to influence his wife's empowerment, ${ }^{14}$ we argue that it could also be directly and indirectly related to their child's well-being. However, we could not locate research from India that investigated the relationship of paternal gender-related attitudes with child undernutrition.

We found that irrespective of the wealth of the household, children having either an empowered mother or a father with higher gender-equitable attitudes had lower odds of stunting and severe stunting compared with children of poorer households with a disempowered mother and a father with lower gender-inequitable attitudes. This suggests that having at least one parent who could create a woman-friendly environment for the child in the household might improve the nutritional status of the child. The importance of having a parent, any parent, with a womanfriendly outlook is thus underscored and the supremacy of the influence of maternal, compared with paternal, characteristics on child health is questioned. Arguably, an empowered mother could have a greater say in household decision-making, thus accessing the resources to take better care of her child. For instance, she could take decisions related to her own health (which could affect the health of the child), what should be cooked in the house (which could affect the child's nutritional status) and decisions directly related to the child's healthcare. This is corroborated by previous research from South Asia highlighting the relationship between women's autonomy and child undernutrition. ${ }^{5}$ On the other hand, a father with greater gender-equitable attitudes could be more flexible with gender roles within the household, thereby being more active in childcare or helping the mother with household chores. Additionally, the nurture and care from the father may reduce the risk of child undernutrition. Previous studies from patriarchal societies such as Malawi have highlighted the benefits of men's involvement in maternal and child health for improved nutritional status. ${ }^{27}$ While such paternal involvement in childcare is likely uncommonly observed in patriarchal societies such as India, a previous study from Pakistan suggested that 
Table 2 Association (adjusted ORs, 95\% Cl) of the groups representing the intersection of maternal autonomy, paternal gender-equitable attitudes and household wealth with stunting and severe stunting among underfives in India ( $n=22867)$

\begin{tabular}{|c|c|c|c|c|c|c|}
\hline \multirow[b]{3}{*}{ Independent variables } & \multicolumn{3}{|c|}{ Stunting } & \multicolumn{3}{|c|}{ Severe stunting } \\
\hline & \multirow[b]{2}{*}{ AOR } & \multicolumn{2}{|l|}{$95 \% \mathrm{Cl}$} & \multirow[b]{2}{*}{ AOR } & \multicolumn{2}{|l|}{$95 \% \mathrm{Cl}$} \\
\hline & & Lower interval & Higher interval & & Lower interval & Higher interval \\
\hline \multicolumn{7}{|c|}{ Intersectional group (reference: concordant-low and non-affluent group) } \\
\hline Concordant-high and non-affluent & 0.90 & 0.79 & 1.04 & 0.80 & 0.67 & 0.94 \\
\hline Concordant-high and affluent & 0.56 & 0.46 & 0.67 & 0.50 & 0.38 & 0.67 \\
\hline Concordant-low and affluent & 0.57 & 0.48 & 0.67 & 0.71 & 0.56 & 0.88 \\
\hline \multicolumn{7}{|l|}{ Gender of the child (reference: male) } \\
\hline Female & 0.93 & 0.86 & 1.00 & 0.90 & 0.82 & 0.99 \\
\hline Age of the mother & 1.01 & 0.99 & 1.02 & 1.00 & 0.99 & 1.02 \\
\hline Other backward classes & 0.87 & 0.79 & 0.96 & 0.88 & 0.78 & 0.99 \\
\hline General & 0.79 & 0.69 & 0.90 & 0.70 & 0.59 & 0.83 \\
\hline \multicolumn{7}{|l|}{ Religion (reference: Hindu) } \\
\hline Muslim & 1.12 & 0.99 & 1.27 & 0.99 & 0.85 & 1.15 \\
\hline Christian & 0.78 & 0.61 & 0.99 & 1.00 & 0.67 & 1.50 \\
\hline Others & 0.90 & 0.71 & 1.13 & 0.95 & 0.70 & 1.29 \\
\hline Mother's BMI & 0.97 & 0.96 & 0.98 & 0.96 & 0.94 & 0.97 \\
\hline Mother's education & 0.71 & 0.65 & 0.78 & 0.63 & 0.56 & 0.70 \\
\hline Father's education & 0.86 & 0.77 & 0.96 & 0.83 & 0.73 & 0.95 \\
\hline
\end{tabular}

BMI, body mass index.

paternal involvement in childcare is crucial for child wellbeing. ${ }^{28}$ The implication then is that among other benefits, children's health will likely improve through efforts to instil more gender-equitable attitudes among men. Indian men's gender-equitable attitudes were found to improve their involvement in women's healthcare, ${ }^{14}$ and also improve women's autonomy related to household decision-making in India, ${ }^{14}$ which in turn might lead to better child health. ${ }^{5}$ While these explanations and learnings from previous studies discuss how maternal and paternal influences, independently, may impact a child's nutritional status, our study was able to highlight that when examined from an intersectional perspective, the child appears to benefit equally from having a parent with a woman-friendly perspective, regardless of the parent's gender. This highlights the contribution of the father's attitude in a realm which is traditionally considered to be heavily influenced by maternal factors.

Moreover, our intersectional analyses allowed us to show that simultaneously occupying a privileged location on two axes (having an empowered mother and a father with a greater gender-equitable attitudes) substantially reduced the odds of child undernutrition, compared with having only either/none such parents. This would be missed in most analyses that estimate the role of maternal and paternal factors independent of each other. A high woman-friendly parental unit likely offers the child greater opportunities to receive nurturing from both the parents and benefit from both maternal and paternal resources for overall well-being, thereby reducing the risk of undernutrition. It is therefore not surprising that children of mothers who did not report greater empowerment and fathers with lower gender-equitable attitudes had the greatest odds of undernutrition.

The strong role played by household wealth was highlighted in our findings. Children belonging to richer households had lower odds of undernutrition compared with those from poorer households, for every combination of maternal empowerment and paternal genderequitable norms. Greater economic resources could create a healthier environment for the child through several pathways, including via increased access to a healthier diet and ability of parents meet the demands of healthcare expenditure. While previous studies from India have shown that children belonging to poorer versus richer households were at greater risk of undernutrition, ${ }^{22} 29$ our intersectional analysis revealed interesting results. We found that children belonging to poorer 
households but having either an empowered mother or a father with a greater gender-equitable attitudes had lower odds of undernutrition compared with children of poorer households and having none such parents. This suggests that despite a lack of economic resources in the household, having an empowered mother or a father with gender-equitable attitudes could act as an unmaterialistic yet invaluable resource promoting the child's health. Previous studies have shown that the need and demand for childcare in low-income families are not different from families with economic privileges, however, they may lack choices due to their pressing need to work more to sustain their family. ${ }^{30}$ However, having an empowered mother or a father having greater gender-equitable attitudes in such households could result in a flexible division of household labour thus creating more ways to negotiate their daily work schedules and devote more time to childcare. Moreover, programmes and policies focused on reducing undernutrition would likely target the poor due to the persistent wealth inequalities in undernutrition in India. ${ }^{31}$ An empowered mother or a father with greater gender-equitable attitudes could be more receptive to the messages from, and more conscientious about accessing the benefits of, these programmes due to their open outlook, thereby reducing the risk of their child's undernutrition. For instance, a father with greater genderequitable attitudes could be more attentive of maternal healthcare related information and actively participate in community events organised locally. Similarly, an empowered mother could have more frequent interaction with the community health workers such as the Accredited Social Health Activists and Anganwadi workers about her own and her child's health. Such empowered mothers might also be more comfortable participating in community events due to the support from husbands with greater gender-equitable attitudes.

Overall, our findings suggest that children with a privileged position in any one of the three intersectional axes (maternal autonomy, paternal gender-equitable attitudes and household wealth) were better off compared with the most disadvantaged children. These children could offset the effects of their disadvantaged position through the privileges gained from the other axes.

\section{Limitations and strengths}

The study has several limitations that need to be considered. First, the cross-sectional nature of the survey limits our ability to draw causal conclusions. However, the statistically significant associations provide evidence supporting the interesting relationship between the intersectional groups and undernutrition among Indian underfives. Second, despite the larger sample of children with anthropometric data we could use only a subsample which had data on gender-related attitudes of the parents, thereby limiting our ability to generalise the findings. Our sample also comprised respondents majorly from rural areas. However, our sample had a good diversity of social groups such as caste, religion, gender and educational attainment that allowed us to draw several interesting conclusions. Third, another limitation of this study is the possibility of social desirability bias in the reports of gender-equitable attitudes among the fathers. Rather than investigating the direct relationship of gender-equitable attitudes with child undernutrition, we examined the influence of belonging to intersectional groups on three axes, with the groups being defined using broad classifications based on the median split of scores. This potentially reduces the effect of social desirability bias on our findings. Therefore, we are confident that our findings are minimally compromised by such a bias. Fourth, we were able to show a statistically significant difference in prevalence of the size $4.2 \%$ and $4.9 \%$ points (for stunting and severe stunting, respectively) at alpha $=0.05$ and power of 0.80 . However, despite the lack of statistical power to estimate smaller differences, we argue that our findings are crucial given that this is the largest publicly available sample for father-mother-child (underfives) triads from India. Lastly, due to the smaller sample size we could not explore the intersection of other social axes such as caste, place of residence, and so on, which could have yielded a more comprehensive picture. Additionally, due to low statistical power we could not separately assess the relationship of discordant-paternal high and discordant-maternal high groups with the outcomes. Nevertheless, we argue that despite the modest sample size we found statistically significant results in our analysis that contribute to learning about an understudied topic. Furthermore, the findings from our analytical models that accounted for several important social factors shed light on the importance of women-friendly parental characteristics in improving child health.

Despite these limitations, to our knowledge, this is the first study to apply the lens of intersectionality to explore the relationship of parental characteristics regarding gender-roles and household wealth with child nutritional status thereby creating new avenues in understanding child undernutrition in India.

\section{Implications and conclusion}

In this paper, we argue that while women's autonomy potentially reduces the risk of child undernutrition, focusing on men's attitudes towards gender equity also holds promise for improvement in child health, especially undernutrition. Therefore, these findings are relevant to the design and reform of a variety of policies such as those that focus on improving women's social status in society, changing men's views about gender roles to be more egalitarian, and reducing wealth-inequity among Indian households. Specifically, our results emphasise that men's involvement in child health could be integrated into existing programmes targeting undernutrition, such as the Integrated Child Development Services. Interventions related to paternal involvement in child care could also be introduced. Local non-governmental organisations could play an active role in the design and demonstration of community-based programmes that 
simultaneously target women empowerment and men's gender-related attitudes. For instance, previous research highlighted that men's involvement in maternal and childcare through policies and interventions changed the perception of men about gender roles and dynamics at the community level. ${ }^{27}$ Finally, our findings open avenues for researchers to conduct further research, especially longitudinal investigation, focused on unpacking the complex process linking parental gender-related perspectives and child undernutrition.

The intersectional lens has allowed us to highlight the impact on child health of a father's gender-equitable attitude despite his wife not being highly empowered. The widespread practice of focusing on maternal characteristics, while occasionally accounting for paternal factors, would miss such insights. Our findings not only underscore how patriarchy is embodied in undernourished children, but also suggest programmatic interventions to address this deep-rooted scourge of India.

\section{Twitter Malavika Ambale Subramanyam @MalavikaSocEpi}

Acknowledgements AJS thanks IIT Gandhinagar for providing the institute fellowship while carrying out this research.

Contributors AJS contributed to conceptualisation, formal analysis, investigation, methodology, project administration, writing-original draft. MS: contributed to conceptualisation, project administration, supervision, writing-review \& editing.

Funding The authors have not declared a specific grant for this research from any funding agency in the public, commercial or not-for-profit sectors.

Competing interests None declared.

Patient consent for publication Not required.

Provenance and peer review Not commissioned; externally peer reviewed.

Data availability statement Data are available in a public, open access repository. All data are publicly available at the Demographic and Health Survey (DHS) website.

Supplemental material This content has been supplied by the author(s). It has not been vetted by BMJ Publishing Group Limited (BMJ) and may not have been peer-reviewed. Any opinions or recommendations discussed are solely those of the author(s) and are not endorsed by BMJ. BMJ disclaims all liability and responsibility arising from any reliance placed on the content. Where the content includes any translated material, BMJ does not warrant the accuracy and reliability of the translations (including but not limited to local regulations, clinical guidelines, terminology, drug names and drug dosages), and is not responsible for any error and/or omissions arising from translation and adaptation or otherwise.

Open access This is an open access article distributed in accordance with the Creative Commons Attribution Non Commercial (CC BY-NC 4.0) license, which permits others to distribute, remix, adapt, build upon this work non-commercially, and license their derivative works on different terms, provided the original work is properly cited, appropriate credit is given, any changes made indicated, and the use is non-commercial. See: http://creativecommons.org/licenses/by-nc/4.0/.

\section{ORCID iD}

Anupam Joya Sharma http://orcid.org/0000-0002-1726-9992

\section{REFERENCES}

1 Swaminathan S, Hemalatha R, Pandey A, et al. The burden of child and maternal malnutrition and trends in its indicators in the states of India: the global burden of disease study 1990-2017. Lancet Child Adolesc Health 2019;3:855-70.

2 How does the world bank classify countries? - world bank data help desk. Available: https://datahelpdesk.worldbank.org/knowledgebase/ articles/378834-how-does-the-world-bank-classify-countries [Accessed 20 May 2021].
3 IIPS and ICF. National family health survey (NHFS-4), 2017.

$4 \mathrm{Kim} \mathrm{R}$, Rajpal S, Joe W, et al. Assessing associational strength of 23 correlates of child anthropometric failure: an econometric analysis of the 2015-2016 national family health survey, India. Soc Sci Med 2019;238:112374.

5 Carlson GJ, Kordas K, Murray-Kolb LE. Associations between women's autonomy and child nutritional status: a review of the literature. Matern Child Nutr 2015;11:452-82.

6 Derné S. Hindu men talk about controlling women: cultural ideas as a tool of the powerful. Sociological Perspectives 1994;37:203-27.

7 Cook RJ, Dickens BM, Fathalla M. Reproductive health and human rights: integrating medicine, ethics, and law, 2011.

8 Tigga PL, Sen J. Maternal body mass index is strongly associated with children Z-cores for height and BMI. Journal of Anthropology 2016.

9 Becker S, Robinson JC. Reproductive health care: services oriented to couples. Int J Gynaecol Obstet 1998;61:275-81.

10 Bustamante-Forest R, Giarratano G. Changing men's involvement in reproductive health and family planning. Nurs Clin North Am 2004;39:301-18.

11 Cham M, Sundby J, Vangen S. Maternal mortality in the rural Gambia, a qualitative study on access to emergency obstetric care. Reprod Health 2005;2:3.

12 Shahjahan M, Kabir M. Why males in Bangladesh do not participate in reproductive health: lessons learned from focus group discussions. Int Q Community Health Educ 2006;26:45-59.

13 Seward N, Neuman M, Colbourn T, et al. Effects of women's groups practising participatory learning and action on preventive and careseeking behaviours to reduce neonatal mortality: a meta-analysis of cluster-randomised trials. PLoS Med 2017;14:e1002467.

14 Chattopadhyay A. Men in maternal care: evidence from India. $J$ Biosoc Sci 2012;44:129-53.

15 Engle PL. The role of men in families: achieving gender equity and supporting children. Gend Dev 1997;5:31-40.

16 Philip S. Making men and masculinities visible: a macro level enquiry into conceptualizations of gender and violence in Indian policies. NORMA 2015;10:326-38.

17 Ganle JK, Dery I. 'What men don't know can hurt women's health': a qualitative study of the barriers to and opportunities for men's involvement in maternal healthcare in Ghana. Reprod Health 2015;12:93.

18 David EJR, Derthick AO. What Is Internalized Oppression, and So What? In: Internalized Oppression, 2018.

19 Desai S, Andrist L. Gender scripts and age at marriage in India. Demography 2010;47:667-87.

20 Collins P. Moving beyond gender: intersectionality and scientific knowledge. Revisioning gender 1999.

21 Crenshaw K. Mapping the margins: intersectionality, identity politics, and violence against women of color. Stanford Law Rev 1991;43:1241.

22 Kanjilal B, Mazumdar PG, Mukherjee M, et al. Nutritional status of children in India: household socio-economic condition as the contextual determinant. Int J Equity Health 2010;9:19.

23 WHO Multicentre Growth Reference Study Group,. WHO child growth standards : length/height-for-age, weight-for-age, weight-forlength, weight-forheight and body mass index-for-age : methods and development 2006.

24 Kabeer N. Resources, Agency, Achievements: Reflections on the Measurement of Women's Empowerment. Dev Change 1999;30:435-64.

25 Filmer D, Pritchett LH. Estimating wealth effects without expenditure data--or tears: an application to educational enrollments in states of India. Demography 2001;38:115-32.

26 StataCorp. Stata Statistical Software:Release 14. Stata Statistical Software, 2015.

27 Mkandawire E, Hendriks SL. A qualitative analysis of men's involvement in maternal and child health as a policy intervention in rural central Malawi. BMC Pregnancy Childbirth 2018;18:37.

28 Jahna A, Aslamb A. Fathers ' perception of child health : a case study in a squatter settlement. Health Transition Review 1995;5.

29 Pal A, Pari AK, Sinha A, et al. Prevalence of undernutrition and associated factors: a cross-sectional study among rural adolescents in West Bengal, India. Int J Pediatr Adolesc Med 2017;4:9-18.

30 Larner M, Mitchell A. Meeting the child care needs of low-income families. Child Youth Care Forum 1992;21:317-34.

31 Kumar A, Kumari D, Singh A. Increasing socioeconomic inequality in childhood undernutrition in urban India: trends between 1992-93, 1998-99 and 2005-06. Health Policy Plan 2015;30:1003-16. 